\title{
Assessment of bone condition by acoustic emission technique: $A$ review
}

\author{
Sharad Shrivastava ${ }^{1}$, Ravi Prakash ${ }^{1}$ \\ ${ }^{1}$ Birla Institute of Technology and Science, Pilani, India. \\ Email: sharadiitkgp@gmail.com, raviprakash.ravi@gmail.com
}

Received 14 February 2009; revised 18 March 2009; accepted 21 March 2009.

\begin{abstract}
The paper deals with the review of acoustic emission technique in biomedical field. The review is done with the aim to provide an overview of the use of $A E$ technique in biomedical field, mainly concentrated on the AE behavior of bone under different loading conditions, its dependence on strain rate, in osteoporosis, monitoring the fracture healing process of bone. The overall conclusion from the review was that almost all the studies in bone indicated that the initial $A E$ occurs only in the plastic region and just prior to yield. That means the use of $A E$ technique for clinical application cannot be considered as a safe technique, but the early occurrence of $A E$ events from callus promises the application of $A E$ technique for monitoring the fracture healing process. The negligible effect of soft tissues on AE response of bone promises $A E$ to become a non-invasive method for assessment of bone condition.
\end{abstract}

Keywords: Acoustic Emission; Assessment; Strain Rate; Callus; Fracture Healing; Osteoporosis

\section{INTRODUCTION}

Bone is primary structural element of human body. The anatomy of human beings is quite well known but the strength and mechanical properties of bones have not been investigated thoroughly. The 206 named bones of skeleton constitutes $18 \%$ of the adult human body weight, only skin and fat $(25 \%)$ and muscles $(43 \%)$ being greater [1]. In biological terms bone is described as a connective tissue and in mechanical terms bone is a composite material with several distinct solid and fluid phases. The mechanical properties of bone have been more extensively investigated than those of any other biological tissue materials. Although our understanding of the mechanical properties and fracture behavior of bone is continuously improving, as yet it is far from complete. As pointed by Hayes, W. C. [2] while fundamental research is needed on many aspects of the mechanical response of the bone, applications of the techniques of analytical and experimental mechanics in this area are made complicated by the fact that bone is highly complex living material.

The initial work in the field of bone biomechanics can be traced back to the $17^{\text {th }}$ century when "attempts to express biological findings in physical terms" [3] were made by the scholars at that time. This philosophical background of the aspect was intensified in the age of determinism which lasted until the middle of the $19^{\text {th }}$ century. One of the main aspects of the research work in that time was to relate the architecture of bone and its mechanical functions. In the year 1832, Bourgery, J. M. [4] in his work on anatomy raised the question of relation between architecture and mechanical functions of bone. In his book on osteology, Ward, F. O. [5] compared the proximal end of the human femur with a crane and he mentioned the compressive and tensile stresses evoked in the bone by loading. In the year 1867, a more detailed analysis of the structure of cancellous bone and its mathematical significance was given by Meyer, G. H. [6] in association with the famous mathematician Culmann.

The industrial revolution took place in the second half of the $19^{\text {th }}$ century. It had an impact on the research works in the bone also. New developments were made in the field of material testing and the new methods were developed for mechanical measurements. For a while, these methods were used to determine the in vitro mechanical properties of bone. The bones were tested under various loading conditions and the ultimate strength of bone was determined by many investigators $[7,8,9,10,11$, 12,13,14,15,16,17,18]. Mc Elhaney, J. H. [19] from his study on the strain rate dependence of the mechanical properties of bone showed that both the compressive strength and modulus of longitudinally oriented compact bone specimens were significantly increased by increasing the strain rate. A critical strain rate for bone has been 
claimed in compression [19], torsion [20] and tension [21]. However Wright, T. M. and Hayes, W. C. [22] found no critical strain rate in tensile tests of bovine bone over a wide strain-rate range.

In the last few decades attempts were made to use the newly developed/improved non-destructive testing techniques to find the mechanical properties of in vivo and in vitro bones. Those include finding the elastic constants using ultrasonic techniques $[23,24,25,26]$, finding the mechanical strength of bone specimens by X-ray computed tomography, etc.

Assessment of in vivo bone condition is one of the research areas, which have attracted many biomedical engineers and clinical orthopaedicians in recent times. Presently the radiological examination is widely used for the assessment of in vivo bone condition [27,28]. In some clinical problems such as diagnosis of the point of clinical union of fracture, the manual assessment of stability is also used along with the radiological examination. However for many applications the radiographic technique was found to be suffered from low sensitivity. For instance, for the evaluation of osteoporosis it requires a minimum loss of $30 \%$ or more of bone mineral content before an unequivocal roentgen logical diagnosis can be made [29].

Monitoring the fracture healing process is another area where the currently used techniques failed to give satisfactory results. Uncertainty regarding the significance of the radiographic and clinical findings may result in unnecessarily long immobilization periods which can produce discomfort and inconvenience for the patients, as well as possible joint stiffness and even permanent loss of motion especially in the elderly.

In certain long bone shaft fractures the healing process is modified by the method of treatment so that the clinical assessment of mechanical integrity is impossible and the interpretation of radiographs may be difficult.
Diaphyseal fractures treated by "rigid" internal fixation always demonstrated this problem, since the fracture cannot be tested mechanically and external callus formation is not seen on radiographs, methods are needed to assess the mechanical integrity of fracture healing in such circumstances, or an unreliable and unsafe rehabilitation programme may be prescribed.

Mechanical impedance, natural frequency, vibration analysis, stress wave propagation, ultrasonic- measurements, impact response technique, electrical potential measurements and mechanical tissue response analysis are some of the techniques, which have been attempted by different investigators for the assessment of in vivo bone condition in the past $[30,31,32,33,34,35,36,37,38$, $39,40]$. However, in all these studies, the intervening soft tissues, whose quantity and quality changes with individual to individual, affected the results. Furthermore some methods were not really non-invasive in nature and some were not practicable for widespread clinical use because of low reliability and complicated instrumentation.

The structure of bone is very much similar to engineering composite materials and is therefore advantageous to use a non-destructive testing technique, which has already proved it usefulness in the field of composite materials testing. Acoustic emission (AE) technique has been used very successfully for the non-destructive evaluation of composites. The relationship between $\mathrm{AE}$ response and mechanical behavior in composite materials has been extensively studied in the past [41]. This paper deals with the review of $\mathrm{AE}$ technique which is to be used for bone assessment. The review has been broadly classified as follows (Figure 1).

\section{ACOUSTIC EMISSION TECHNIQUE}

The AE technique is the sound produced by materials as they fail. A familiar example is the audible cracking

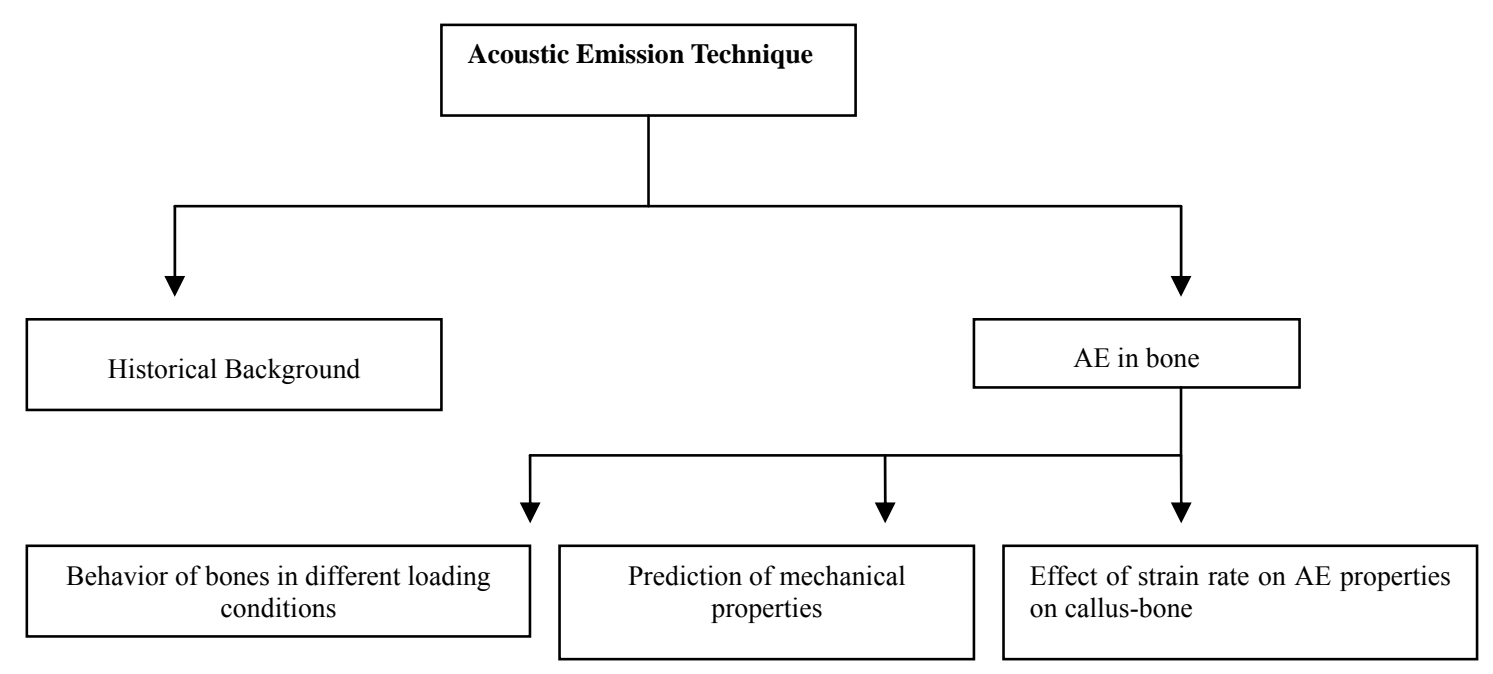

Figure 1. Broad classification of the review study. 
noise from wood. Almost all engineering materials generate acoustic emissions but unlike wood, the sound is too faint to be heard without sensitive electronic monitors. Acoustic emission waves can be detected by means of remote piezoelectric sensors and their source can be located by timing the wave arrival at several sensors. Thus $\mathrm{AE}$ provides a unique method of recognizing when and where deformation is taking place as a structure is stressed.

The first systematic investigations of AE phenomenon was made in 1950 by Kaiser, J. [42] at the technical university of Munich. In his investigations, the noise emitted by the deformation of materials was examined by means of electronic equipment capable of detecting inaudible ultrasonic signals. Kaiser, while working with polycrystalline specimens concluded that acoustic vibrations originate in grain boundary interfaces and was believed to be associated with the interaction induced between interfaces by applied stresses. He noted that, for a given materials, characteristics spectra of frequency and amplitude existed. One of the important observations made in his study was that irreversible processes were involved with AE phenomenon; an effect later came to be known as Kaiser Effect. The universality of the AE phenomenon, as recognized by Kaiser, leads to a very wide range of applicability. AE has been recorded from hundreds of materials-metals, composites, ceramics, plastics, glasses, building materials, biological materials in vitro and in vivo as well as from multi material structures and joints between different materials [43]. Compared to other NDT techniques which rely on extraneous energy for the illumination of defect; $\mathrm{AE}$ enjoys the unique feature that the defect makes its own signal. This leads to a natural complementary between $\mathrm{AE}$ and other methods.

\section{ACOUSTIC EMISSION DETECTION AND SIGNAL PROCESSING}

Figure 2 [44] shows the method of detection of acoustic emission events by remote piezoelectric transducers. Here, an AE source generates an expanding spherical

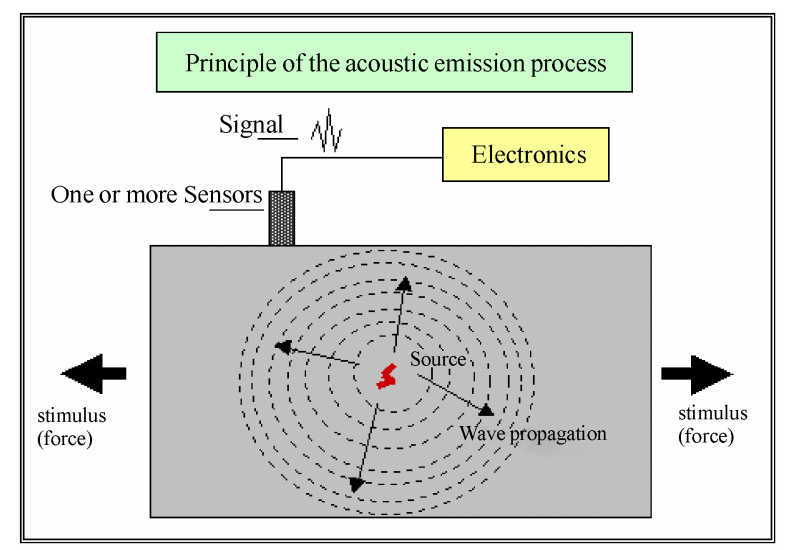

Figure 2. Detection of acoustic emission event by remote piezoelectric transducers (source: 44 ). wave packet losing intensity at a rate of $r^{-2}$. When this wave reaches the body boundary, a surface wave packet is created, either Rayleigh or Lamb wave type depending on the thickness. This method is mainly used for flaw monitoring in inaccessible areas. The individual signal has a short duration at the source and a corresponding broad spectrum which typically extends from zero frequency to many megahertz. The form of the signal at the point of detection is a damped oscillation, developed in the structure according to known principles of acoustic wave propagation. Figure 3 [44] shows the signal waveform of one acoustic emission event and different parameters normally measured to characterize the acoustic emission source.

\section{ACOUSTIC EMISSION IN BONE}

Hanagud, S., et al. [45] using bovine femora first demonstrated detectable acoustic emissions from bone. His work made the way for other investigators to use the $\mathrm{AE}$ technique for characterization of bone and also to explore the possibilities of using it as a tool for clinical orthopaedicians to detect bone abnornamilities $[46,47,48$, 49,50]. Knet-s, I. V., et al. [46] has shown that the character of the fracture surface depends on the orientation of the load relative to the direction of the osteons, the rate of loading, and the geometrical shape of the actual sample. They concluded that the most promising approach in testing the internal state of a bone is acoustic emission, sometimes also known as the method of stress-wave emission. This approach involves recording of deformation noise in the material due to the development and further propagation of structural defects. These defects may include dislocations or cracks appearing in the course of loading. This study was the first work to visualize the degree of micro cracks development in bone tissue subjected to longitudinal extension. This experimental work was only visualized for longitudinal loading and the deformation rate considered was also very low $(1 \mathrm{~mm} / \mathrm{min})$. The study was not conducted for higher strain rates. In another investigation Hanagud, S., et al. [50] conducted AE tests on carefully prepared bone specimens subjected to bending loads. Their specimen included femur from cattle and cadavers. They compared the AE patterns from 60 perfect and defective specimens. The result clearly indicated that the development of an effective early diagnostic tool for osteoporosis was possible by using $\mathrm{AE}$ technique.

Thomas, R. A., et al. [51] studied the acoustic emissions from fresh bovine femora and its clinical applications. They employed a more sophisticated set up of AE technique by including both amplitude and pulse width distribution to investigate whole fresh bovine femora which were loaded by compression and bending. They found that both the amplitude distribution and pulse width distribution results of fresh bone had clearly shown characteristic spectra which could be used for the early detection of bone abnormalities such as fracture and osteoporosis. 


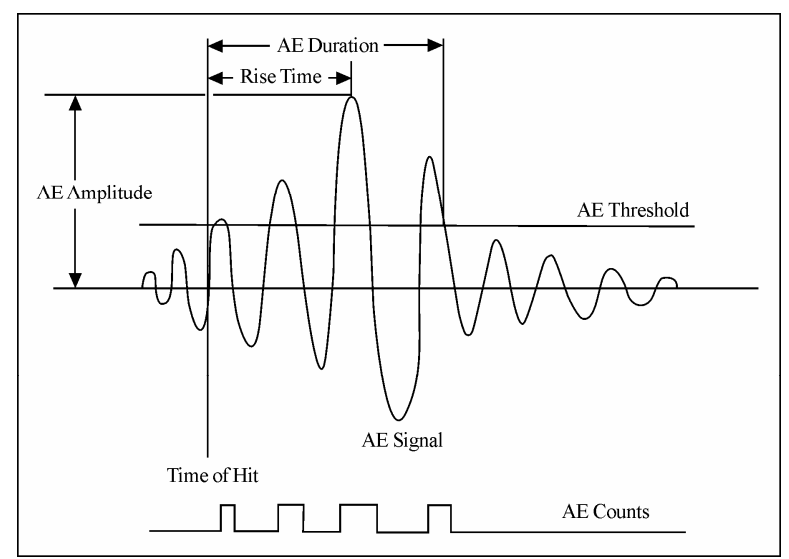

Figure 3. Signal waveform for one acoustic emission event (source: 44).

Yoon, H. S., et al. [52] developed a new AE technique for applications to human and animals both non-invasively and non-traumatically. Bones from several different species of animals and different kinds in the same species were tested to obtain AE parameters. Their results indicated that the AE amplitude distributions of all the bones are similar, somewhat independent of the species of animals and kind in the same species and however different from those of those materials such as metals, ceramics and plastics. The technique was found useful for the diagnosis of micro fractures, such as stress fractures in the tibia of runners, which were not detectable by conventional X-ray technique until they begun to heal. Moreover conventional techniques would require introducing some additional stresses in to the part of the body under examination, which also introduces additional trauma to the patient. In their technique the low intensity ultrasonic pulses were injected through an $\mathrm{AE}$ transducer, instead of applying loads to the bone under tests. The loading as pulses reduced the introduction of trauma to the live subject. Another receiving AE transducer was used to collect five types of useful AE data: per-event- distribution of counts, peak amplitude, energy and pulse duration, and cumulative counts vs time.

Netz, P. [53] monitored the AE response of canine femora in torsion at 6 degrees per second. His work demonstrated that the $\mathrm{AE}$ events occur in the non-linear plastic portion of the load deflection curve. Wright, T. M., et al. [54] monitored the permanent deformation of compact bone using $\mathrm{AE}$ technique. Uniaxial tension tests were performed on standardized specimens of bovine harvesian bone to examine the contributions of mineral and collagen to permanent deformation in bone and to monitor the damage mechanisms occurring in permanent deformation using $\mathrm{AE}$ technique. Their results were consistent with a two-phase model for bone in which the mineral behaves as an elastic-perfectly plastic material when bound to the collagen fiber matrix. The AE events occurred just prior to the yield point and continued during yielding. Significant AE counts occurred again just prior to fracture. No emissions occurred in the elastic region and few occurred in the major portion of plastic region between yield and fracture. To monitor micro cracks in the specimen they used AE and plotted graphs. Figures 4,5 [54] show stress vs. strain and cumulative acoustic emission counts vs. strain curves for one of the control specimens and decalcified specimens. These graphs indicate the similarity between the acoustic emission data of the bones prior to fracture. Figure 6 [54] shows stress strain plots based on the mean values from Table 1 [54]. The limitation of their work lies in the hy pothesis that the mineral only exhibit elastic-perfectly plastic behavior in conjunction with collagen. They conducted experiments on control, decalcified and deprotenised groups of specimens with the same hypothesis. The fact is that the deprotenised groups of specimens behave in brittle manner. Hence they suggested further studies to be undertaken to examine the contributions of mineral and collagen for permanent deformation in the bone. The two phase model used could be used to study the quasistatic tensile behavior of compact bone but more work could have been carried out for higher strain rates responses before coming to any conclusion.

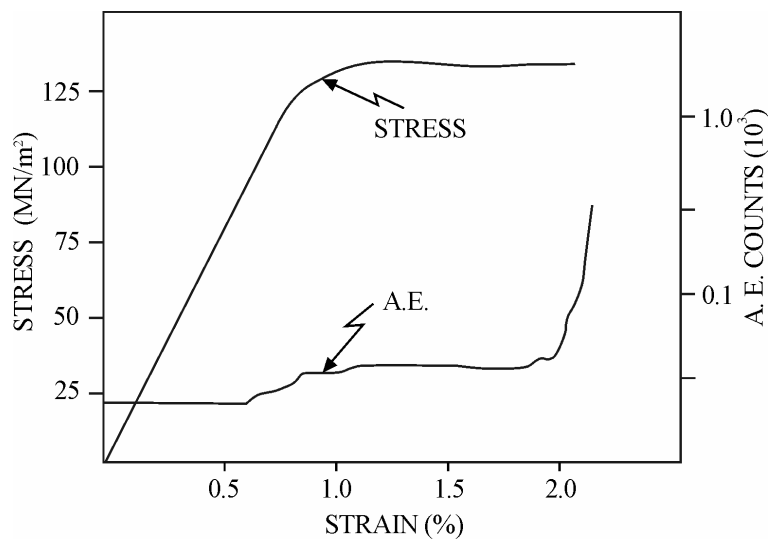

Figure 4. Stress vs strain and acoustic emission counts vs strain curves for one of the control specimens (source: 54).

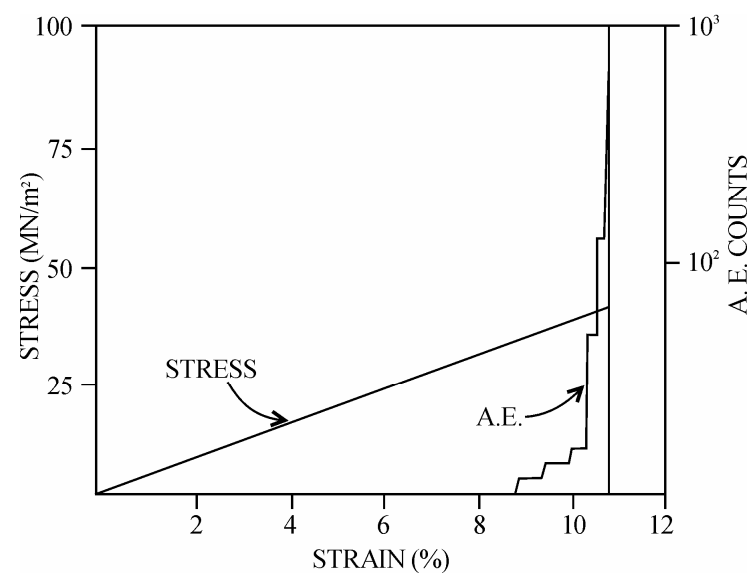

Figure 5. Stress vs strain and acoustic emission counts vs strain curves for one of the decalcified specimens (source: 54 ). 


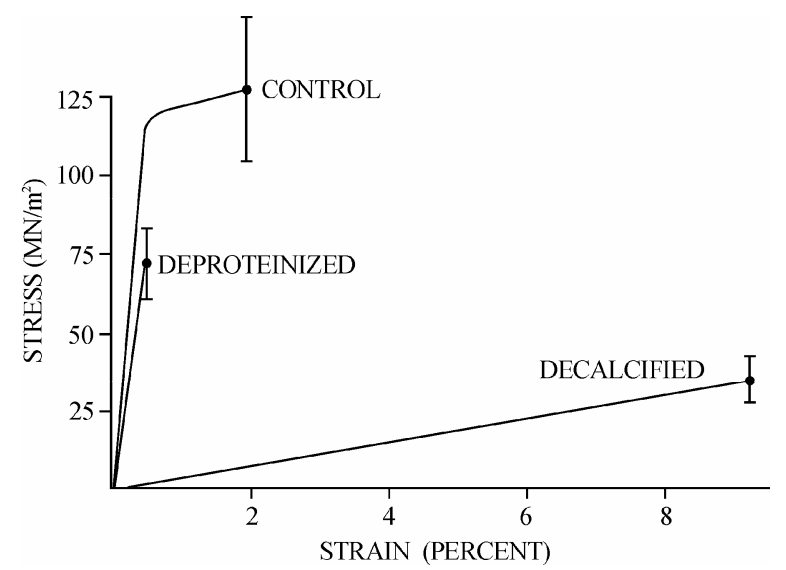

Figure 6. Stress-strain curves for the three test groups constructed from the mean values in Table 1. Error bars are shown for ultimate stress values (source: 54 ).

Table 1. Mechanical properties of decalcified and partially deproteinized bovine bones (source: 54 ).

\begin{tabular}{lccc}
\hline & control & decalcified & Deproteinized \\
\hline No of specimens & 7 & 11 & 10 \\
Yield stress & $118(9.8)$ & - & - \\
Yield strain & $0.544(0.150)$ & - & - \\
Ultimate stress & $128(15.6)$ & $34(7.5)$ & $71(11.5)$ \\
Ultimate strain & $2.02(0.924)$ & $9.247(1.524)$ & $0.956(0.342)$ \\
Elastic modulus & $20.6(2.76)$ & $0.37(0.05)$ & $11.3(3.15)$ \\
Plastic modulus & $0.66(0.357)$ & - & - \\
\hline
\end{tabular}

It is an established fact that the ultimate tensile strength of bone is dependent on the applied strain rate. Based on these Fisher, R. A., et al. [55] studied the effect of using two different strain rates on the AE in bones. In their work bovine cortical bone was milled in to standard tensile specimens which were tested at two different strain rates while being monitored with $\mathrm{AE}$ equipment. They found that the amplitude distribution of the $\mathrm{AE}$ events in bone is dependent on strain rate. Greater number of events occurred with the slower strain rate but the events were of lower amplitude than those emitted during the more rapid strain rate. Here also the initial AE occurred well in to the plastic region of the stress-strain curve near the point of fracture of the tensile specimens. It was evident from the study that if acoustic emission technology is to be utilized clinically for the assessment of fracture healing; careful selection of rate of loading would be necessary. Furthermore the study indicated that acoustic emission response was different at different strain rates. As the emissions did not occur until failure was imminent, it indicates that Acoustic emission technology is not suitable for evaluating the integrity of bone. The limitation included that the specimens taken were of very large sizes to minimize the stress concentrations effects of normal bone architecture. They did their work at only two different strain rates $(0.0001 / \mathrm{s}$ and $0.01 / \mathrm{s})$; therefore no conclusion could be made for broad range of strain rates.

Later on Nicholls, P. J., et al. [56] studied the AE properties of callus. In their work, rabbits with 45 degree midshaft oblique osteotomies were strained in shear while monitoring for $\mathrm{AE}$ events. Each fracture remained essentially quiet until over $50 \%$ of load to failure had been applied. They suggested that since callus formation during fracture healing takes important role in the healing process, the $\mathrm{AE}$ from callus may have clinical applications. The limitation of the study lies in the test method used for evaluating bone. As bone is a non-homogeneous substance, it is very difficult to evaluate with instruments which have been designed for homogeneous substances. A test method should be so designed that eliminates background noise, such as slippage of specimen in the grips and motion of the transducers on the bone surface. This hampers reproducibility of acoustic emission patterns. In most of the AE studies of bone the bone has been tested without the surrounding soft tissues. But in the case of clinical applications of AE, one cannot separate the bone from soft tissues and hence the tests should be performed with soft tissues. Hanagud, S., et al. [57] studied these phenomena. They used freshly dissected rabbit tibia and femur with soft tissues. Tests were conducted through bending load. They found that the soft tissues of 2 to $9 \mathrm{~mm}$ thickness did not affect the bone's AE response.

A study of bone-tissue samples by Martens, M. [58] used acoustic emission for to study the mechanical behavior of femoral bones in bending loading. Ono, K. [59], provided an insight about the fundamental theories and equations related to acoustic emission. Stromsoe, K., et al. [60], worked on bending strength of femur using non invasive bone mineral assessment.

The work done till this time demonstrated that the safe use of $\mathrm{AE}$ technique for the non-destructive testing of bone is impossible because the AE events occurred only after plastic deformation occurred.

Lentle, B. C. [61], University of British Columbia used acoustic emission to monitor osteoporosis. He devised a method for in vivo diagnosis of patients using AE technique, which could also predict the severity of osteoporosis.

Table 2. The predictive capability of acoustic emissions expressed in terms of the specimen's fatigue life (source: 71).

\begin{tabular}{lcccc}
\hline & $\begin{array}{c}\text { Maximum } \\
\text { stress(MPa) }\end{array}$ & $\begin{array}{c}\mathrm{N}_{\mathrm{F}} \text { Fatigue } \\
\text { life [cycles] }\end{array}$ & $\begin{array}{c}\text { NP Fracture } \\
\text { onset via } \\
\text { AE [cycles] }\end{array}$ & $\begin{array}{l}\text { Predictive } \\
\text { of fatigue life] }\end{array}$ \\
\hline Specimen 1 & 55 & 26363 & 22580 & $85 \%$ \\
Specimen 2 & 61 & 35020 & 33382 & $95 \%$ \\
Specimen 3 & 66 & 4737 & 2989 & $63 \%$ \\
Specimen 4 & 71 & 600 & 402 & $67 \%$ \\
\hline
\end{tabular}


Table 3. A statistically significant effect of time on these mechanical properties was detected. Within a row, values with differing letters are significantly different from each other $(\mathrm{P}<0: 05)$ (Source: 65).

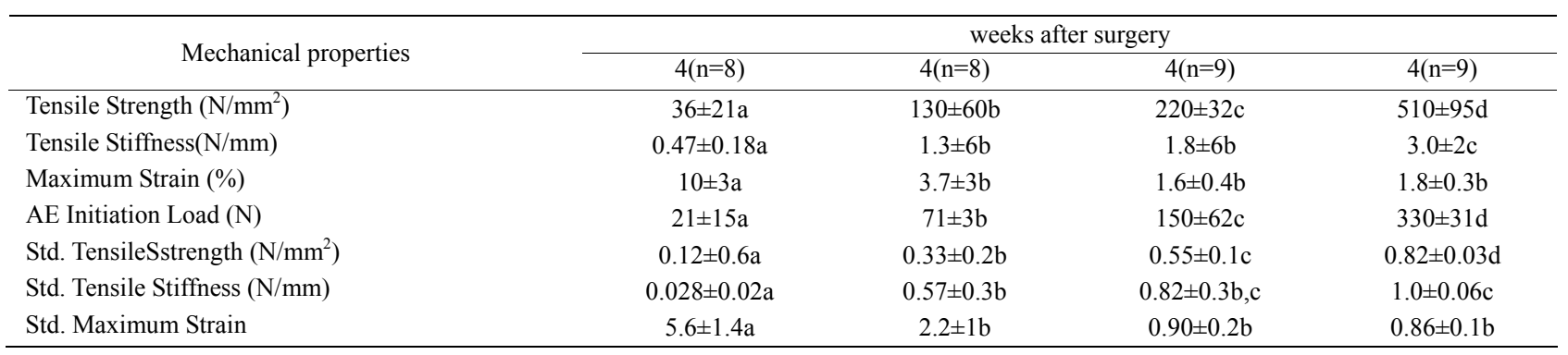

Table 4. Ash content was calculated by (ash density/apparent density $\hat{A}$ 100). A statistically significant effect of time on these mechanical properties was detected. Within a row, values with differing are significantly different from each other letters $(\mathrm{P}<0: 05)$ (Source: 65).

\begin{tabular}{lcccc}
\hline \multirow{2}{*}{$\begin{array}{l}\text { Mechanical } \\
\text { properties }\end{array}$} & $4(\mathrm{n}=9)$ & $6(\mathrm{n}=9)$ & $8(\mathrm{n}=10)$ & $12(\mathrm{n}=10)$ \\
\cline { 2 - 5 } & & & & \\
\hline $\begin{array}{l}\text { Apparent } \\
\text { density } \\
\left(\mathrm{g} / \mathrm{cm}^{3}\right)\end{array}$ & $0.42 \pm 0.07 \mathrm{a}$ & $0.67 \pm 0.07 \mathrm{~b}$ & $1.2 \pm 0.1 \mathrm{c}$ & $1.2 \pm 0.08 \mathrm{c}$ \\
$\begin{array}{l}\text { Ash density } \\
\left(\mathrm{g} / \mathrm{cm}^{3}\right)\end{array}$ & $0.14 \pm 0.04 \mathrm{a}$ & $0.40 \pm 0.06 \mathrm{~b}$ & $0.82 \pm 0.08 \mathrm{c}$ & $0.88 \pm 0.06 \mathrm{c}$ \\
$\begin{array}{l}\text { Ash content } \\
(\%)\end{array}$ & $33 \pm 4 \mathrm{a}$ & $59 \pm 5 \mathrm{~b}$ & $71 \pm 1 \mathrm{~b}, \mathrm{c}$ & $73 \pm 1 \mathrm{c}$ \\
\hline
\end{tabular}

Acoustic emission was being used to predict changes in mechanical properties due to fatigue $[62,63,64]$. Watanabe, Y., et al. [65] used AE technique to predict mechanical properties of fractures. Experimentally produced fractures of femur in rats were tested in tension and in torsion at 4, 6, 8 and 12 weeks after fracture. AE signals were monitored during these mechanical tests. The values for load and torque at the initiation of the AE signal were defined as new mechanical parameters. Tensile strength, tensile stiffness, and torsional stiffness were found to increase with time. They focused on how AE signals can help a surgeon to remove the external fixators in the sense that AE signals can be used to monitor healing of bones. Table 3 [65] indicates a statistically significant effect of time on these mechanical properties. Table 4 [65] indicates the calculated ash content and the statistically significant effect of time on the mechanical properties of bone. The data obtained by them were compared to the original values and were found out to be almost the same. The study was a first step towards the establishment of AE testing as a means of predicting the callus strength. The two parameters exhibited strong and positive linear correlation with tensile strength and torque. The linear correlations suggested that it may be possible to use AE technology to evaluate fracture healing process, following osteotomy surgery. There were still many issues which needed to be resolved to make it clinically viable.
Kevin S. C. K., et al. [66] developed an acoustical technique for the measurement of structural symmetry of hip joints. Since, these techniques depend very much on the intensity and quality of sounds emitted from the joints under investigation. They developed an acoustical technique for the measurement of relative acoustic transmission across both hips of the test subjects while they were subjected to an external vibratory force applied at the sacrum. The merit of this approach was that it allows direct comparison of the sound signals transmitted across both hips regardless of the measure of the input vibratory force. Simultaneously, other acoustic techniques like scanning acoustic microscopy $[67,68]$ acoustic mapping $[69,70]$ was being used to predict and study mechanical properties of tissues and bone.

Ozan A. [71] worked on a hypothesis that an increase in micro damage activity during repeated loading of bone will signal the approaching stress fracture. Interception with the training regime prior to the incidence of the fracture as signaled by acoustic emissions would reduce the time necessary for recuperation. Acoustic emission was used for real time monitoring of micro cracks. They used acoustic emission technique to predict the failure of cortical bone. Table 2 [71] indicates the predictive capability of acoustic emissions expressed in terms of the specimen's fatigue life.

Information was collected on all acoustic events, regardless of whether they originated from micro damage or somewhere else and then signals originating from the micro damage were isolated. The rest of the irrelevant signals were filtered out based on their average frequency, duration, amplitude, and intensity. With the non-micro damage signals removed from the data, we were able to determine the number acoustic events related to bone damage as well as the time at which they occurred. Specially designed software is yet to be developed which will segregate the zones of micro damage. Fracture healing and prediction of healing time of fractures were increasingly being studied. A review by Browne, M., et al. [72] on acoustic emission's capability to monitor bone degradation and bone fatigue provided us information with latest developments in this field.

In 2004, Franke, R. P., et al. [73] used acoustic emission for in vivo diagnosis of the knee joint. For the as- 
sessment of the tribological knee function and by the probability of fracture of the femur an adapted Acoustic Emission Measurement System named Bone Diagnostic System (BONDIAS) was developed. This system makes the in vivo analysis of the medical status possible. Different mechanisms of cracking were accompanied by different acoustic emission from human femora as shown in literature. An acoustic emission signal typical of crack initiation is shown in Figure 7 [73]. This Figure is indicative of the acoustic emission from healthy knee joint cartilage after a sudden change from a two leg stand to a one leg stand. It is characterized by a very short rise time and an exponential decrease of the amplitudes. From the medical point of view such mechanical loads are regarded as non destructive although there is already crack initiation in the interface of the compact and the trabecular system of the bone. These micro cracks seem to be essential for the physiological bone remodeling. For the description of the development of bone strength over time it is necessary to assess both the threshold of crack initiation and the conditions for crack propagation. The sudden change in amplitude indicates high thickness of the cartilage layer. There are several advantages of the diagnostic procedure by $\mathrm{AE}$ when compared with established conventional methods:

1) No pain is caused by this procedure.

2) This procedure is non-destructive. Mechanical load even beyond the crack initiation threshold are typical of day to day life and necessary for the physiological bone remodeling to avoid the degeneration of the bone and joint system.

3) There is no health burden through ionizing radiation as is unavoidable with X-ray examination and CT.

4) There is no danger of infection since this is a non-invasive examination.

5) The time required for the assessment of the acoustic emission behavior and analyses of data are of the order of seconds to minutes.

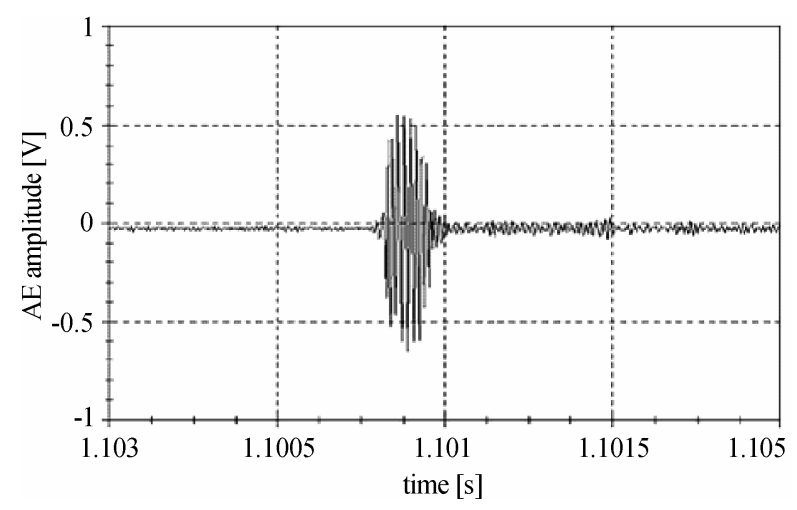

Figure 7. Acoustic emission from healthy knee joint cartilage deformation after the sudden change from a two leg stand to a one leg stand (source: 73).
6) The expenses for the AE measurement system are small compared to X-ray systems.

7) The costs per examination including a detailed diagnosis are well below costs of other diagnostic procedures and there is no danger of infection leading to further costs, as happens with invasive methods, e.g. endoscopic examinations.

8) Diagnostic (Real time) monitoring of bone and joint training of sports professionals becomes possible.

The disadvantage of the measurement system suggested was that the physician will be left with the bundle of data and the task to evaluate the AE.

Tatarinov, A., et al. [74] proposed multiple acoustic wave method for assessing long bones. The method was based on measurement of ultrasound velocity at different ratio of wavelength to the bone thickness and taking into account both bulk and guided waves. They assessed the changes in both the material properties related to porosity and mineralization as well as the cortical thickness influenced by resorption from inner layers, which are equally important in diagnosis of osteoporosis and osteopenia. More in vivo studies on animals and human volunteers has to be carried out before the proposed method could be made clinically usable. The advantage of the method proposed was that it allowed assessment of changes in both the material properties related to porosity and mineralization as well as cortical thickness influenced by resorption from inner layers, which are equally important in diagnosis of osteoporosis and other bone osteopenia. The method could also be used for diagnosis of bone condition if the contribution of soft tissues and topographical heterogeneity in real bones are considered. The method had a potential for better detection of early stage of osteoporosis in long bones. Singh, V. R. [75] reviewed an acoustic imaging technique known as acoustic stress wave propagation technique which was used for bone examination. The technique was developed with the view to solve the problems encountered with the conventional technique like X-rays. As bone is a heterogeneous, complex and fibrous tissue, determination of very small abnormalities viz. shape and size of bone defects, is not usually possible by means of conventional $\mathrm{X}$-ray technique.

In 2006, Azra Alizad, et al. [76] studied the change in resonant frequencies of a bone due to change in its physical properties caused due to a fracture. Experiments were conducted on excised rat femurs and resonance frequencies of intact, fractured, and bonded (simulating healed) bones were measured. These experiments demonstrated that changes in the resonance frequency indicated bone fracture and healing. The fractured bone exhibits a lower resonance frequency than the intact bone, and the resonance frequency of the bonded bone approaches that of the intact bone. The graphs are indicative of the result (Figures 8,9) [76], that the frequency re- 
sponse of a cut femur is less than the intact femur. The proposed method may be used as a remote and non invasive tool for monitoring bone fracture and healing process, and the use of focused ultrasound enables one to selectively evaluate individual bones. The proposed method offers several advantages over vibrational methods using external mechanical excitation. The ultrasound can be applied remotely and directly to the bone under test, thus avoiding interference of overlaying muscle or other tissues on force distribution. Furthermore, in contrast to traditional methods in which it is difficult to target small bones and to access them, the proposed method allows application of excitation force directly and selectively to the intended bone. The acoustic method for measuring
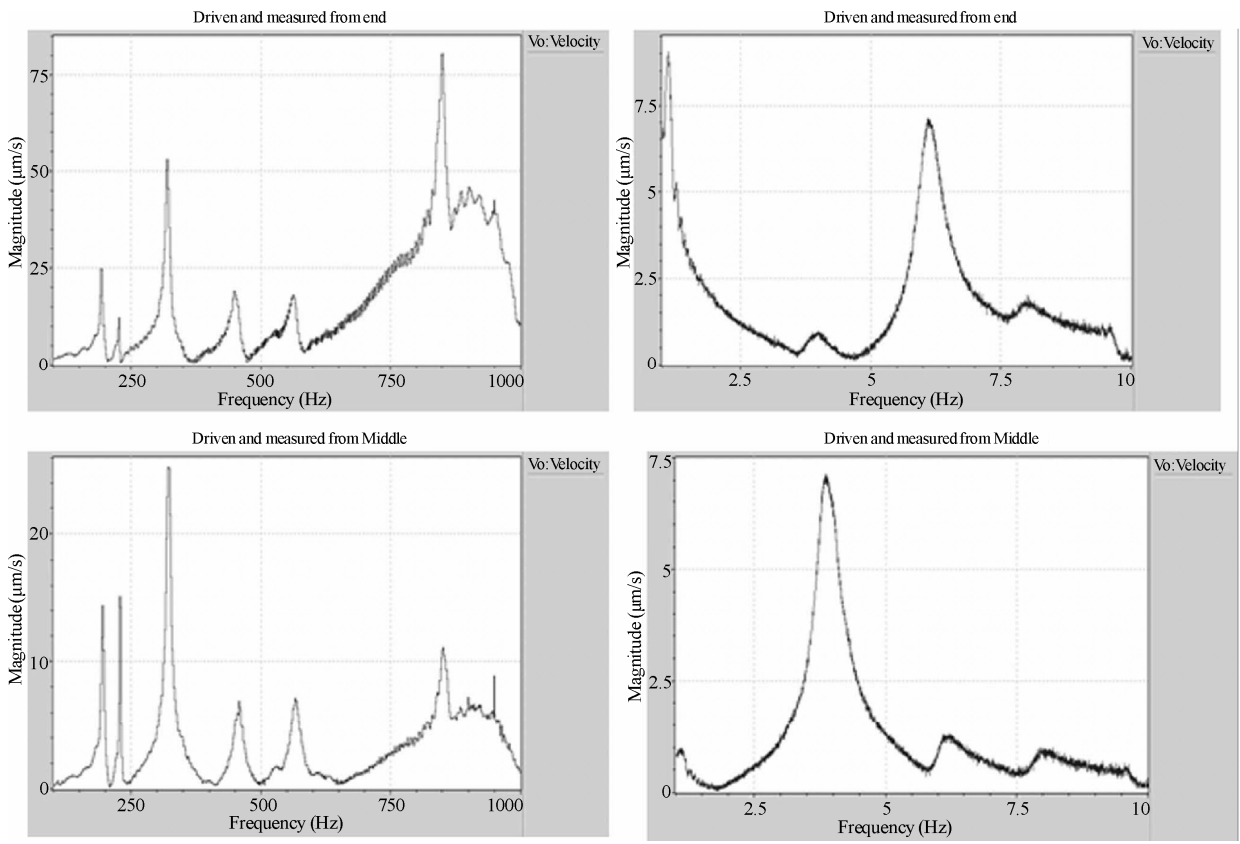

Figure 8. Frequency response of the intact femur A. The plots show the motion of the intact femur vs frequency. These Fig plots indicate peaks at $925 \mathrm{~Hz}, 4.2 \mathrm{kHz}$, and $8.1 \mathrm{kHz}$. Peaks of motion below $700 \mathrm{~Hz}$ were explored and found not to be related to the femur. Top left: Driven and measured at the end of the femur at frequency range of $100 \mathrm{~Hz}$ to 1000 $\mathrm{Hz}$. Top right: Driven and measured at the end of the bone at $1 \mathrm{kHz}-10 \mathrm{kHz}$. Bottom left: Driven and measured at bone midpoint at $100 \mathrm{~Hz}-1000 \mathrm{~Hz}$. Bottom right: Driven and measured at bone midpoint at $1 \mathrm{kHz}-10 \mathrm{kHz}$ (source: 76).
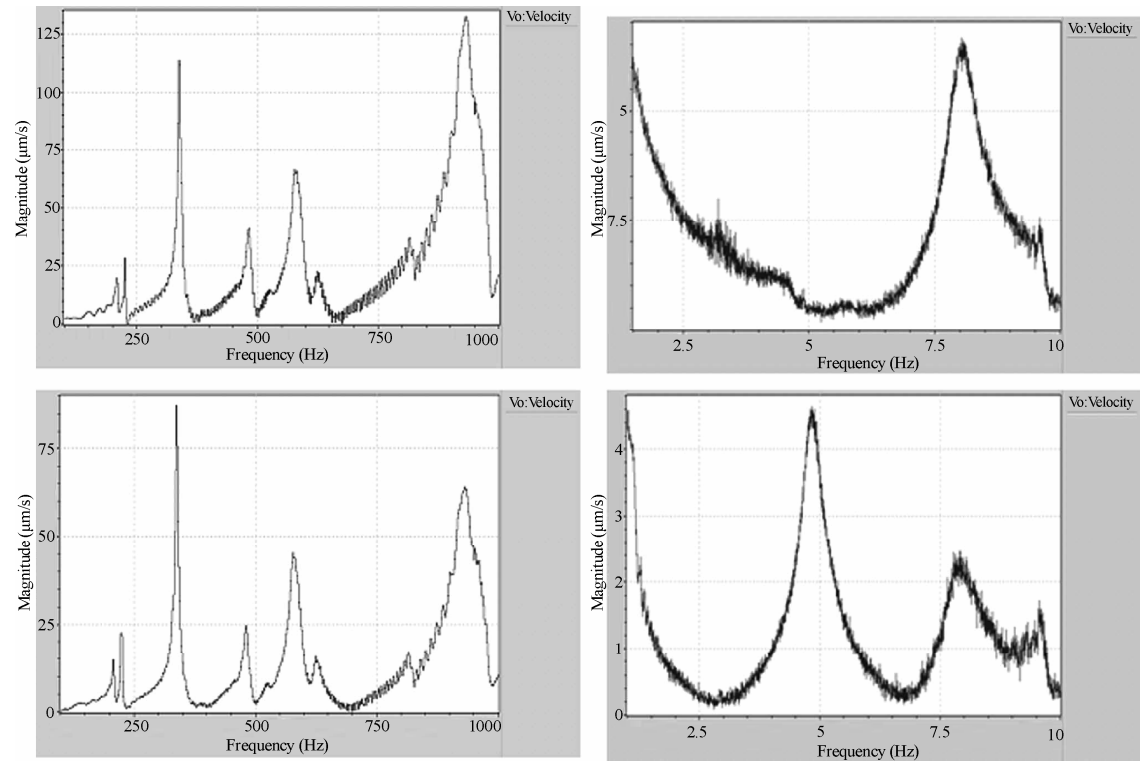

Figure 9. Frequency response of the cut femur (source: 76). 
bone response is suitable for in vivo applications as long as one take the frequency response of the surrounding structures in to account. An advantage of acoustic motion detection method is that it does not require a direct path to the bone because the acoustic emission produced by the bone travels easily in every direction, thus the location of hydrophone is not critical. Further investigations are needed to demonstrate the applicability of the proposed method for evaluation of bone quality in human body. The boundary conditions of bone to body must also be considered before applying the proposed method.

In 2008, Dipan Bose, et al. [77] studied the effect of valgus bending and shear loading on knee joint. They used acoustic sensors to determine the failure timing of soft tissues attached to femur and tibia. The failure timing was determined based on the knee injury mechanism due to valgus loading. At the estimated time injury, the corresponding values of $\alpha_{\text {valgus_fail, }}, d_{\text {shear_fail, }}, M_{\text {valgus_fail, }}$ and $V_{\text {shear_fail }}$ were designated as the failure parameters of the knee. Numerical methods with accurate geometric and material properties could be implemented to simulate and further extend the injury threshold to alternate loading detection. Elmar K. Tschegg, et al. [78] did stiffness analysis of tibia implant system under cyclic loading. $\mathrm{He}$ used a bio- mechanical system integrated with acoustic emission sensors at the screw head. 3 sequences of loading were used to determine when the locking screws break. Data was obtained from the acoustic sensors onto a data acquisition board and were processed using a acoustic emission software. This acquired data was used to determine as to which screw is bearing the load and as to when does the screw break.

\section{CONCLUSIONS}

- Many investigations carried out in the field "Assessment of bone condition" are mainly in vitro studies. For any method which is going to be used in clinical practice, a thorough experimental study with animals and/or a clinical study with human volunteers are very much essential.

- The AE is very much dependent on the strain rate.

- AE technique is highly sensitive to specimen damage and cracks and detects them even before visual detection.

- Diagonostic (Real time) monitoring of Bone is possible.

- It is non-destructive and helps us to predict the time length of the healing process.

- It has no harmful effects unlike X-rays, which have radiation effects on patients.

- The emissions from the callus during fracture healing, gives its possibility to be clinically used.

\section{FUTURE RESEARCH DIRECTIONS}

- Many researchers have used this technique for in vitro as well as in vivo characterization of bone. However, the clinical application of the technique was not fully investigated. The time of occurrence of initial $\mathrm{AE}$ and the $\mathrm{AE}$ response of bone under different loading conditions at different strain rates are not well established. So focus can be on finding the exact time of occurrence of initial $\mathrm{AE}$ with respect to the stress/strain curve and the $\mathrm{AE}$ behavior under a suitable loading condition at different strain rates.

- In the case of in vivo studies, the AE response of callus is not thoroughly investigated. Also it is necessary to conduct an experimental study with laboratory animals/volunteers or patients to prove the clinical usage of AE.

\section{ACKNOWLEDGEMENT}

The authors wish to acknowledge Mr. Sudeep Mohapatra \& Mr. Kaushik. V. for their help. Financial assistance provided by Department of Science and Technology, Government of India is also gratefully acknowledged.

\section{REFERENCES}

[1] F. G. Evans, (1982) Bones and bones, Trans. of ASME, J. Biomechanical Engg., 104/1, 1-5.

[2] W. C. Hayes, (1978) Biomechanical measurements of bone, in CRC Handbook on Engg., in Medicine and Biology, Section B. Instruments and Measurements, B. N. Feinberg and D. G. Fleming (eds.) CRC Press, Florida, 1, 333-372.

[3] C. J. Singer, (1959) A short history of scientific ideas to 1900, Oxford University Press, New York.

[4] J. M. Bourgery, (1832) Traite Complet de l' Anatomie de 1' Homme. I. Osteologie, Paris.

[5] F. O. Ward, (1838) Outlines of human osteology, London, 370.

[6] G. H. Meyer, (1867.) Die Architektur der spongiosa, Arch. Anat. Physiol. Wiss. Med., 34, 615-628.

[7] K. K. Hulsen, (1896) Specific gravity, resilience and strength of bone, bull, Biol. Lab. St. Petersburg, 1, 7-35.

[8] F. G. Evans, (1973) Mechanical properties of bone, Springfield, I. L.

[9] C. O. Carothers, F. C. Smith, and P. Calabrisi, (1949) The elasticity and strength of some long bones of the human body, Nav. Med. Res. Inst. Rept. NM 001056.02.13.

[10] F. G. Evans and M. Lebow, (1951) Regional differences in some of the physical properties of the human femur, J. Appl. Physiol., 3, 563-572.

[11] F. G. Evans and M. Lebow, (1952) The strength of human bone as revealed by engineering techniques, Am. J. Surg., 83, 326.

[12] F. G. Evans, (1964) Significant differences in the tensile strength of adult human compact bone, in Proceedings of the First European Bone and Tooth Symposium, H. J. J. Blackwood (ed.), Pergamon, Oxford, 319-381.

[13] E. D. Sedlin and C. Hirsch, (1966) Factors affecting the determination of the physical properties of femoral cortical bone, Acta. Othop. Scand., 37, 29-48.

[14] E. D. Sedlin, (1965) A rheological model for cortical bone, Acta. Othop. Scand., 33, 5-77. 
[15] A. H. Burstein, J. D. Currey, V. H. Frankel, and D. T. Reilly, (1972) The ultimate properties of bone tissue: The effects of yielding, J. Biomechanics, 5, 35-44.

[16] A. H. Burstein and V. H. Frankel, (1968) The viscoelastic properties of some biological materials, Ann. N. Y. Acad. Sci., 46, 158-165.

[17] A. H. Burstein, V. H. Frankel, and D. T. Reilly, (1973) Failure characteristics of bone tissue, in Perspectives in Biomedical Engg, R. M. Kenedi, (ed.), University Park Press, London, 131-134.

[18] A. H. Burstein, D. T. Reilly, and M. Marten, (1975) Aging of bone tissue: Mechanical properties, J. Bone J. Surg, 58, 82-86.

[19] J. H. Mc Elhaney, (1966) Dynamic response of bone and muscle tissue, J. Appl. Physiol., 21, pp. 1231-1236.

[20] M. M. Panjabi, A. A. White, and W. O. Southwick, (1973) Mechanical properties of bone as a function of rate of deformation, J. Bone. J. Surg, 55(A), 322-330.

[21] R. D. Crowinshield and M. H. Pope, (1974) The response of compact bone in tension at various strain rates, Ann. Biomed.Engg., 2, 217-225.

[22] T. M. Wright and W. C. Hayes, (1976) Tensile testing of bone over a wide range of strain rates: effects of strain rate, Microstructure and Density, Med. Biol. Engg., 14, 671-680.

[23] S. B. Lang, (1970) Ultrasonic method for measuring elastic coefficients of bone and results on fresh and dried bovine bones, IEEE Trans. Biomed. Engg., 17, 101-105.

[24] H. S. Yoon and J. L. Katz, (1976) Ultrasonic wave propagation in human cortical bone: I, Theoretical Considerations for Hexagonal Symmetry, J. Biomechanics, 9, 407-412.

[25] H. S. Yoon and J. L. Katz, (1976) Ultrasonic wave propagation in human cortical bone: II, Measurements of Elastic Properties and Micro hardness, J. Biomechanics, 9, 459-464

[26] R. B. Ashman, J. D. Corin, and C. H. Turner, (1987) Elastic properties of cancellous bone: measurement by an ultrasonic technique, J. Biomech, 20(10), 979-986.

[27] E. Lachmann and M. Whelan, (1936) The roentgen diagnosis of osteoporosis and its limitations, Radiology, 26, 165-177.

[28] E. Lachmann, (1955) Osteoporosis: The potentialities and limitations of its roentgenologic diagnosis, Amer. J. Roentgenology, 74, 712-715,

[29] I. I. H. Chen and S. Saha, (1987) Wave propagation characteristics in long bones to diagnose osteoporosis, J. Biomech., 20(5), 523-527.

[30] F. Y. Wong, S. Pal, and S. Saha, (1983) The assessment of in vivo bone condition in humans by impact response measurement, J. Biomech., 16(10), 849-856.

[31] L. L. Stern and J. Yageya, (1980) Bioelectric potentials after fracture of tibia in rats, Acta Orthop. Scand., 51, 601-608.

[32] S. Saha and R. R. Pelker, (1976) Measurement of fracture healing by the use of stress waves, $22^{\text {nd }}$ Annual ORS, New Orleans, Louisiana.

[33] D. A. Sonstegard and L. S. Mathews, (1976) Sonic diagnosis of bone fracture healing-A preliminary study, $\mathrm{J}$. Biomech. 9, 689-694.

[34] N. Guzelsu and S. Saha, (1981) Electromechanical wave propagation in long bones, J. Biomech., 14, 19-33.
[35] G. T. Anast, M. S. Fields, and Siegel, (1958) .Ultrasonic technique for the evaluation of bone fracture, Amer. J. Physical. Med., 37, 157-159.

[36] S. Saha, V. V. Rao, V. Malakanok, B. D. Gross, and J. A. Albright, (1982) Ultrasonic evaluation of fracture healing, Transactions of the $28^{\text {th }}$ Annual Meeting of the Orthopedic Research Society, ORS, Chicago, 259.

[37] O. O. A. Oni, A. Graebe, M. Parse, and P. J. Gregg, (1989) Prediction of the healing potential of closed adult tibia shaft fractures by bone scientigraphy, Clinical Orthopedics and Related Research, 239-245.

[38] S. M. Bentzen, I. Hivid, and J. Jorgensen, (1987) Mechanical strength of tibial trabecular bone evaluated by X-ray computed tomography, J. Biomech., 20, 743-752.

[39] T. Sekiguchi and T. Hirayama, (1979) Assessment of fracture healing by vibration, Acta Orthop.Scand., 50, 391-398.

[40] R. J. Donarski, (1989) Bone Fracture measurement using mechanical vibration, $\mathrm{Ph}$. D. Thesis, University of Kent at Canterbury, UK

[41] R. Prakash, (1980) Non destructive testing of composites, Composites, 10, 217-224.

[42] J. Kaiser, (1950) Untersuchungen uber das auftreten gereausen bein Zugersuch, Ph. D. Thesis, Technische Hutchshule, Munich.

[43] A. A. Pollock, (1979) An introduction to acoustic emission and a practical example, J. Environmental Sciences, March/April, 1-4.

[44] S. Radhakrishnan, (1992) The assessment of bone condition by acoustic emission and acousto-ultrasonic techniques. Ph. D. Thesis, Banaras Hindu University.

[45] S. Hanagud, R. G. Clinton, and J. P. Lopez, (1973) Acoustic emission in bone substance, Proceedings of Biomechanics Symposium of the American Society of Mechanical Engineers, ASME, New York, 74.

[46] I. V. Knet-s, U. E. Krauya, and Y. K. Vilks, (1975) Acoustic emission in human bone tissue upon lengthwise stretching, Mekh. Polim, 4, 685-690.

[47] U. E. Kruya and Y. A. Lyakh, (1978) Acoustic emission in human bone tissue, Mekh. Polim., 1, 109-112.

[48] A. Peters, (1982) Acoustic emission technique and fracture healing, Med. Biol. Engng. Comput, 20, 8.

[49] T. M. Wright and J. M. Carr, (1983) Soft tissue attenuation of acoustic emission pulses, Trans. of ASME J. Biomech. Engg, 105(1), 21-23.

[50] S. Hanagud, G. T. Hannon, and R. G. Clinton, (1974) Acoustic emission and diagnosis of osteoporosis, Proceedings of Ultrasonics Sym., 77-80.

[51] R. A. Thomas, H. S. Yoon, and J. L. Katz, (1977) Acoustic emission from fresh bovine femora, Proceedings of Ultrasonics Symp. IEEE Cat.No. TICH12G4-ISU, 237-240.

[52] H. S. Yoon, B. R. Caraco, and J. L. Katz, (1980) Further studies on the acoustic emission of fresh animal bone, IEEE Trans. Sonics, Ultrasonic, SU-27, 160.

[53] P. Netz, (1979) The diaphyseal bone under torgue, Acta Orthop. Scand. Suppl., 176, 1-31.

[54] T. M. Wright, F. Booburgh, and A. H. Burstein, (1981) Permanent deformation of compact bone monitored by acoustic emission, J. Bomech, 14, 405-409. 
[55] R. A. Fischer, S. W. Arms, M. H. Pope, and D. Seligson, (1986) Analysis of the effect of using two different strain rates on the acoustic emission in bone, J. Biomech., 19(2), 119-127.

[56] P. J. Nicholls and E. Berg, (1981) Acoustic emission properties of callus, Med. Biol. Engg. Comput, 19, 416-418.

[57] S. Hanagud, R. G. Clinton, M. D. Chouinard, E. Berg, and P. J. Nicholls, (1977) Soft tissues and acoustic emission based diagnostic tools, 1977 Ultrasonics Symposium Proceedings, IEEE CAT. No. 77CH1264-ISU, 242-245.

[58] M. Martens, R. van Audekercke, P. de Meester, J. C. Mulier, (1986) Mechanical behaviour of femoral bones in bending loading, Journal of Biomechanics, 19(6), 443-454.

[59] K. Ono, (1979) Fundamentals of acoustic emission, Los Angeles (CA), UCLA, 167-207.

[60] K. Stromsoe, A. Hoiseth, A. Alho, and W. L. Kok, (1995) Bending strength of the femur in relation to non-invasive bone mineral assessment, Journal of Biomechanics, 28(7), 857-861.

[61] B. C. Lentle, Diagnosis of osteoporosis using acoustic emission, The University of British Columbia, Patent no A61B8/08, 1999.

[62] J. G. Wells, (1985) Acoustic emission and mechanical properties of trabecular bone, Biomaterials, 6, 218-24.

[63] I. Leguerney, K. Raum, A. Saied, H. Follet, G. Boivin, and P. Laugier, (2003) Evaluation of human trabecular bone properties by scanning acoustic microscopy, J. Bone Min. Res., 18, S187.

[64] R. M. Rajachar, D. L. Chow, C. E. Curtis, N. A. Weissman, and D. H. Kohn, (1999) Use of acoustic emission to characterize focal and diffuse micro damage in bone, in: Acoustic Emissions: Standards and Technology Update, West Conshohocken, PA: American Society for Testing and Materials, 3-19.

[65] Y. Watanabe, S. Takai, Y. Arai, N. Yoshino, and Y. Hirasawa, (2001) Prediction of mechanical properties of healing fractures using acoustic emission, Journal of Orthopedic Research, 19, 548-553.

[66] S. C. K. Kevin, H. Xiaolin, C. Y. C. Jack, and H. E. John, (2003) Acoustic transmission in normal human hips: Structural testing of joint symmetry, Medical Engineering \& Physics, 25(10), 811-816.
[67] S. Bumrerraj and J. L. Katz, (2001) Scanning acoustic microscopy study of human cortical and trabecular bone, Ann. Biomed. Engg, 29(12), 1034-1042.

[68] I. Eckardt and H. J. Hein, (2001) Quantitative measurements of the mechanical properties of human bone tissues by scanning acoustic microscopy, Ann. Biomed. Engg., 29(12), 1043-1047.

[69] Y. Xia, W. Lin, E. Mittra, B. Demes, B. Gruber, C. Rubin, and Y. Qin, (2003) Performance of a confocal acoustic mapping in characterization of trabecular bone quality in human calcaneus, J. Bone Min. Res, 18, S209.

[70] L. Cardoso, F. Teboul, L. Sedel, C. Oddou, and A. Meunier, (2003) In vitro acoustic waves propagation inhuman and bovine cancellous bone, J. Bone Min. Res, 18(10), 1803-1812.

[71] A. Ozan, (2005) Acoustic emission based surveillance system for prediction of stress fractures, $\mathrm{Ph}$. D. Nicholas Wasserman, The University of Toledo Annual report.

[72] M. Browne, A. Roques, and A. Taylor, The acoustic emission technique in orthopaedics-a review, J. Strain Analysis, 40(1).

[73] R. P. Franke, P. Dörner , H.-J. Schwalbe, and B. Ziegler, (2004) Acoustic emission measurement system for the orthopedical diagnostics of the human femur and knee joint, University of Ulm, Dept. of Biomaterials, Ulm, Germany, Bad Griessbach, Germany, University of Applied Science Giessen, Giessen, Germany.

[74] A. Tatarinov, S. Noune, and S. Armen, (2005) Use of multiple acoustic wave modes for assessment of long bones: Model study, Journal of Ultrasonics, 43, 672-680.

[75] V. R. Singh, (1989) Acoustical imaging techniques for bone studies, Applied Acoustics, 27, 119-128.

[76] A. Alizad, M. Walch, J. F. Greenleaf, and M. Fatem (2006) Vibrational characteristics of bone fracture and fracture repair: application to excised rat femur, Journal of Bio Medical Engineering, Trans ASME, 128.

[77] D. Bose, K. Bhalla, C. D. Untaroju, B. J. Ivarsson, and J. R. Crandall, (2008) Injury tolerance and moment response of knee joint to combined valgus brnding and shear loading, Journal of BioMedical Engineering, 130.

[78] E. K. Tschegg, S. Herndler, P. Weninger, M. Jamek, S. Stanzl- Tschegg, H. Redl, (2008) Stiffness analysis of tibia implant system cylical loading, Material Science and Engineering C, 28, 1203-1208. 